\title{
PSA Doubling Time Less Than or Equal to 6 Months
}

National Cancer Institute

\section{Source}

National Cancer Institute. PSA Doubling Time Less Than or Equal to 6 Months. NCI

Thesaurus. Code C146718.

An indication that the number of months that a subject's blood concentration of prostate specific antigen took to double was six months or less. 